\title{
Why do female mice mate with multiple males?
}

\author{
Kerstin E. Thonhauser • Shirley Raveh • Attila Hettyey • \\ Helmut Beissmann • Dustin J. Penn
}

Received: 17 April 2013 /Revised: 8 July 2013 / Accepted: 8 July 2013 / Published online: 9 August 2013

(C) The Author(s) 2013. This article is published with open access at Springerlink.com

\begin{abstract}
Females often show multi-male mating (MMM), but the adaptive functions are unclear. We tested whether female house mice (Mus musculus musculus) show MMM when they can choose their mates without male coercion. We released 32 females into separate enclosures where they could choose to mate with two neighboring males that were restricted to their own territories. We also tested whether females increase MMM when the available males appeared unable to exclude intruders from their territories. To manipulate territorial intrusion, we introduced scent-marked tiles from the neighboring males into males' territories, or we rearranged tiles within males' own territories as a control. Each female was tested in treatment and control conditions and we conducted paternity analyses on the 57 litters produced. We found that $46 \%$ of litters were multiply sired, indicating that multiple paternity is common when females can choose their mates. Intrusion did not increase multiple paternity, though multiple paternity was significantly greater in the first trial when the males were virgins compared to the second trial. Since virgin male mice are highly infanticidal, this finding is consistent with the infanticide avoidance hypothesis. We also found that multiple paternity was higher
\end{abstract}

Communicated by C. Soulsbury

K. E. Thonhauser $(\bowtie) \cdot$ S. Raveh $\cdot$ A. Hettyey $\cdot$ H. Beissmann $\cdot$

D. J. Penn

Konrad Lorenz Institute of Ethology, Department of Integrative Biology and Evolution, University of Veterinary Medicine, Vienna, Savoyenstraße 1a, 1160 Vienna, Austria

e-mail: kerstin.thonhauser@gmx.at

S. Raveh

Department of Environmental Sciences, Zoology and Evolution, University of Basel, Vesalgasse 1, 4051 Basel, Switzerland

A. Hettyey

"Lendület" Evolutionary Ecology Group, Plant Protection Institute, Centre for Agricultural Research, Hungarian Academy of Sciences, Budapest, Hungary when competing males showed small differences in their amount of scent marking, suggesting that females reduce MMM when they can detect differences in males' quality. Finally, multiple paternity was associated with increased litter size but only in the intrusion treatment, which suggests that the effect of multiple paternity on offspring number is dependent on male-male interactions.

Keywords Polyandry · Multiple mating · Male quality · Infanticide avoidance $\cdot$ Scent marking $\cdot$ Sexual conflict

\section{Introduction}

The adaptive significance of multi-male mating (MMM) or polyandry is unclear and controversial (Jennions and Petrie 2000; Hosken and Stockley 2003; Simmons 2005; Gowaty 2012). Unlike males, females are not expected to increase their reproductive success by mating with multiple individuals (Bateman 1948; Trivers 1972). Moreover, polyandry can incur a number of costs for females, in terms of time and energy expenditure (Daly 1978), elevated risks of predation (Rowe 1994), injuries (Siva-Jothy 2006), and sexually transmitted diseases (Magnhagen 1991), suggesting that there are compensating benefits for females. Several nonmutually exclusive hypotheses have been proposed to explain how females can potentially gain fitness benefits from polyandry (Jennions and Petrie 2000; Simmons 2005). MMM could provide females with direct benefits, such as parental care, nuptial gifts, or other resources from males (Arnqvist and Nilsson 2000; Hosken and Stockley 2003). In nonresource-based mating systems, polyandry might function to increase females' fertility (fertility assurance hypothesis) (Hoogland 1998) or to obtain a variety of indirect, genetic benefits for offspring (Simmons 2005), such as eliciting sperm competition to gain "good genes" (Kempenaers et al. 1992), increasing genetic compatibility 
of maternal and paternal genomes (Zeh and Zeh 1997), including inbreeding avoidance (Tregenza and Wedell 2002), and increasing offspring genetic diversity (Yasui 1998, 2001). Most studies on polyandry have focused on birds and insects, whereas relatively little attention has been paid to mammals (Clutton-Brock and McAuliffe 2009) or sexual conflict hypotheses (Arnqvist and Rowe 2005). Sexual conflict hypotheses suggest that polyandry may be due to sexual coercion, so that females obtain no benefits (Wolff 1985; Smuts and Smuts 1993; Clutton-Brock and Parker 1995), or it may function as an alternative mating tactic (Taborsky et al. 2008) to reduce sexual harassment (convenience polyandry) (Thornhill and Alcock 1983) or infanticide (infanticide avoidance hypothesis) (Hrdy 1979; Agrell et al. 1998). Infanticide is the main cause of offspring mortality in many mammals, and polyandry has evolved more often in mammal species whose young are vulnerable to infanticide (Wolff and Macdonald 2004). However, there are surprisingly few experimental tests of whether polyandry functions to reduce infanticide or sexual coercion in any species. Here, we conducted a study with wild-derived house mice (Mus musculus musculus) to test whether females show MMM when they can choose their mates and are not constrained by sexual coercion, and whether multiple paternity affects offspring number or size when females can select their own mates.

Male house mice are territorial, and females usually mate with the dominant, territorial male, though sometimes females also mate with neighboring territorial males (Oakeshott 1974; Bronson 1979; Potts et al. 1991; Montero et al. 2013). Surveys in wild populations of house mice (Mus domesticus) have found that 6 to $43 \%$ (mean $25 \%$ ) of litters are multiply sired (Dean et al. 2006; Firman and Simmons 2008a). It is unclear why there is so much variation in multiple paternity among wild populations. This variation may be due to changes within females' MMM (conditional mating tactic) or differences between females (heritable or nonheritable personality trait) (McFarlane et al. 2011). It could also be due to differences in social or ecological conditions, as multiple paternity has been found to be correlated with population density (Dean et al. 2006; but see Firman and Simmons 2008a). Females may increase MMM under high density because dominant males can no longer defend their territories from intruders (Anderson 1961), and since females have less protection, they likely face more sexual coercion and risk of infanticide (Calhoun 1962; Ebensperger 1998). Infanticide is very common in mice (Huck et al. 1982; Elwood and Ostermeyer 1984; Manning et al. 1995), and several studies suggest that males kill pups that are not likely to be their offspring. For example, virgin males are highly infanticidal (Labov 1980; Huck et al. 1982; vom Saal and Howard 1982; Elwood and Ostermeyer 1984; Elwood 1985), whereas copulation reduces infanticidal behavior (Soroker and Terkel 1988). Territorial males kill pups outside their own territory, and nonterritorial males commit infanticide when they have not sired any offspring (Manning et al. 1995). Although it is often suggested, it is not known whether female house mice show more MMM when they encounter strange or infanticidal males or whether MMM reduces their risk of infanticide. A study on bank voles (Myodes glareolus) examined the consequences of monogamy versus polyandry and found that offspring of socially polyandrous females had higher survival than offspring from socially monandrous females (all litters were genetically polyandrous) (Klemme and Ylönen 2010). This finding supports the infanticide avoidance hypothesis; however, to explain the variation in multiple paternity, studies are also needed to test whether females are more likely to mate multiply when they perceive a higher risk of infanticide from males.

MMM has been shown to provide several indirect, genetic benefits in female house mice. First, females have increased mean pup survival when they mate with three different males within one estrus cycle compared to females that mate three times with the same male, indicating that polyandry increases offspring viability (Firman and Simmons 2008c). Second, paternity is biased towards nonsiblings when a female mates with both a sibling and a nonsibling, indicating that polyandry facilitates inbreeding avoidance and enhances the genetic compatibility (Firman and Simmons 2008b). Third, female house mice from polyandrous selection lines (16 generations) have increased reproductive benefits compared to females from monandrous selection lines, as their sons achieve higher reproductive success under natural conditions (Firman 2011). However, in all these studies, matings were arranged and it is not known whether multiple paternity provides indirect, genetic benefits when females are able to select their own mates - though the benefits may be even greater compared to when females are forced to mate with randomly selected males in terms of quality. Females show preferences for males of high quality (Ilmonen et al. 2009), and female mate preferences can provide indirect benefits (Drickamer et al. 2000), but it is unclear how variation in male quality affects female MMM or the consequences of multiple paternity. Male mice scent mark their territories and countermark the marks of intruding males (Gosling 1982; Hurst 1990), and females use males' scent marks to recognize territorial males (Drickamer 1992) and to assess males' competitive ability (i.e., males' ability to exclude intruders) (Rich and Hurst 1998; Rich and Hurst 1999). Females may prefer to mate with competitive, territorial males to reduce their risk of infanticide ("pup defense hypothesis") (Ebensperger 1998), as well as obtaining indirect benefits. Female mice also use male scent marking to assess other aspects of male quality, including health (Zala et al. 2004) and genetic disease resistance (Zala et al. 2008a), and females may not show MMM when they can detect differences in the quality of the 
available males. Also, females may be more likely to engage in extra-pair matings when they have a poor quality mate ("trade- up hypothesis") (Kempenaers et al. 1992). Thus, previous studies indicate that female mice can obtain indirect, genetic benefits by MMM, but studies are still needed to determine whether MMM is influenced by variation in male quality (or females' perception of male quality) and how multiple paternity affects offspring fitness when females can select their mates.

In our study, we allowed female mice (wild-derived $M$. musculus musculus) to choose to mate with either one or two neighboring males, which both had their own territory but were restricted from leaving it, and we conduced genetic paternity analyses to determine whether females produce single- or multiple-sired litters (we assume that multiple-sired litters were more likely to be the result of MMM than single-sired litters). We also aimed to test whether females show more MMM, estimated by multiple paternity, when males are unable to defend their territories and exclude intruders, as occurs in high population densities. To test this hypothesis, we experimentally exchanged scent marks between the neighboring males' territories to simulate intrusion and manipulated males' apparent ability to exclude intruders (territorial intrusion). For controls, we relocated males' scent marks within their own territories. The experimental manipulation may alter females' perception of males' quality (in particular, their ability to defend their territory) and apparent risk of infanticide. We expected that if females use intruders' marks to assess males' ability to defend their territories and the risk of infanticide, then females should be more likely to have multiple-sired litters when males are unable to prevent intrusion. We also quantified male scent marking (as a measure of males' quality) to test whether differences in male quality affected the rate of multiple paternity. As only few studies have investigated the consistency or repeatability of females' MMM (Dietrich et al. 2004; Whittingham et al. 2006), we tested each female under territorial intrusion and control conditions. Finally, we examined whether multiple paternity resulted in increased number of offspring when females could select their own mates, as predicted by the fertility assurance, the intrinsic male quality, and the genetic compatibility hypotheses.

\section{Methods}

Experimental animals and housing

All experimental animals were F1 from wild-derived house mice (M. musculus musculus), which were trapped at 14 locations within a $500-\mathrm{m}$ radius in Vienna $\left(48^{\circ} 12^{\prime} 38^{\prime \prime} \mathrm{N}\right.$; $\left.16^{\circ} 16^{\prime} 54^{\prime \prime} \mathrm{E}\right)$ and crossed between sites. The resulting F1 mice were weaned at the age of $21 \pm 1$ days and were thereafter housed individually in standard mouse cages (type II cages,
$26.5 \times 20.5 \times 14 \mathrm{~cm})$ under standard conditions $(12: 12 \mathrm{~h} \mathrm{light}$ cycle) until the experiment was conducted. All cages were equipped with wooden bedding (ABEDD), wood shavings, and food (Altromin rodent diet 1324) and water ad libitum. We conducted ear punches for individual identification, and tissues were collected and stored at $-20{ }^{\circ} \mathrm{C}$ for subsequent genetic analyses. Animals were between 3 and 5 months old when the experiment began. Mice were released into seminatural enclosures where the experiment was conducted.

\section{Experimental mate choice assay}

Each female $(N=32)$ could choose to mate with either one or both of two males $(N=64)$, which were located in two neighboring territories. Each territory $(1 \times 1.7 \times 0.8 \mathrm{~m})$ contained one nest box, one shelter, one mouse cage, one water dispenser, food (Altromin rodent diet 1324), and nesting material (Fig. 1). The males' enclosures were separated from each other by an opaque plastic divider to prevent them from entering and marking each other's territories. The divider had four holes ( $4 \mathrm{~cm}$ in diameter) at the base, which were mesh-sealed to allow visual and olfactory contact between males. Females could move freely between the males' territories through a small passage (plastic tube installed at the bottom of the divider, $3 \mathrm{~cm}$ diameter), whereas the males were prevented from entering the passage by collars $(2.5$ mm-wide cable ties with two attached wires that provided a mechanical barrier at the opening of the tube). Males were collared 2 days prior to their introduction to provide them with sufficient time to become habituated to the collar. A separate shelter cage was placed in each male's territory, which was only accessible to females through a narrow tube entrance that allowed females to escape sexual harassment.

\section{Scent marks and simulated intrusion}

To collect scent marks, we placed 18 PVC tiles $(10 \times 10 \mathrm{~cm})$ on the floor of each male's enclosures along the borders and next to nesting sites, covering approximately $11 \%$ of the enclosure's surface area (Fig. 1). Each tile was individually labeled underneath and was assigned to an exact position within the enclosure. Males were introduced into the enclosures 2 days before the females to enable them to scent mark their compartment and to establish a territory. Simultaneously to male introduction, $20 \mu \mathrm{l}$ of female urine (pool of seven females collected on five consecutive days) were deposited between the nest box and the shelter as female urine has been shown to stimulate males to increase scent marking (Zala et al. 2008b). In the experimental intrusion treatment $(N=32$ females), the males' tiles were exchanged with those of their neighbor's compartment (to simulate intrusion), while in the controls ( $N=32$ females), the males' tiles were collected and replaced within their own compartment. Tile shifting began at 


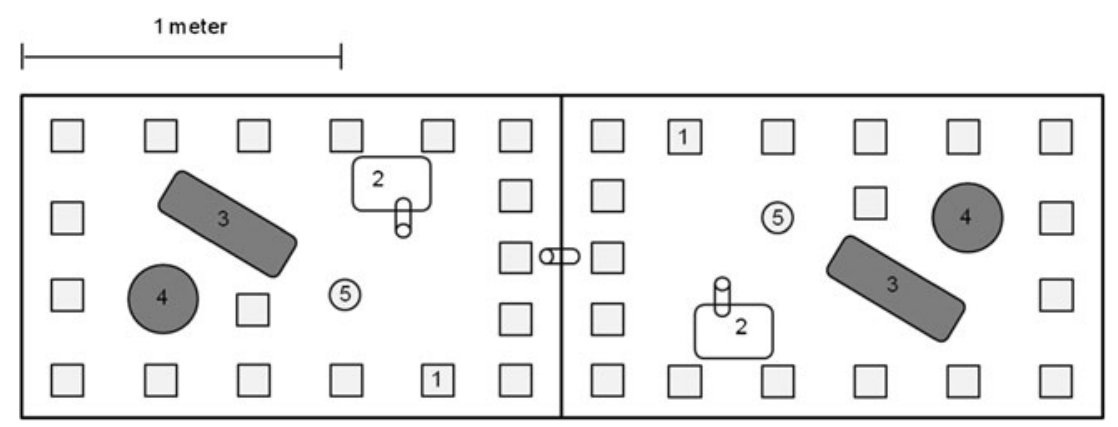

Fig. 1 Neighboring males' compartments with a connection tube that allowed females to move between the male territories. Both compartments contained 18 tiles (1), a cage accessible only to females (2), a shelter box (3), a nest box (4), and a water dispenser (5). In the intrusion treatment, all the tiles in the two males' compartment were exchanged with each other, whereas in the controls, the tiles were rearranged within the males' own compartments day 3 of the experiment, shortly before females were released into the experiment, and was conducted on a daily bases around noon, when animals were inactive. To prevent spreading scent among the tiles and enclosures, observers wore oneway plastic shoe covers and tiles were handled with one-way latex gloves. We took photographs of all tiles before relocating them to assess the amount of males' scent marking for 6 days starting at the day of female introduction.

\section{Experimental design}

Each of the 32 females was used in two trials, once in the intrusion treatment and once with a different pair of males under control conditions (within-subject design). The time between the first and the second trial was 2 months. The order of treatments versus control was determined by applying stratified randomization to avoid sequential effects. Due to space limitations, we could not test all 32 females simultaneously, so we ran two groups per trial, where we tested 16 females and 32 males each. The number of treatment and controls was balanced within groups. The 64 males were also tested twice; however, males were assigned to new pairs for the second trial. We ensured that none of the experimental animals were familiar with or related to one another and male pairs were body-mass-matched within $0.5 \mathrm{~g}$. Male body mass was measured shortly before they received their collar, and female body mass was measured at the day we released them into the experiment. We determined the differences between female and male body mass by calculating the mean body mass of male pairs and subtracting female body mass. All females had given birth to one litter before this experiment to control for potential order effects due to comparing virgin versus nonvirgin females. The males were all virgins on the first trial and at least $61 \%$ were sexually experienced in the second trial (61\% of males sired offspring, but the number of males that mated could be higher). The mice in the experiment were allowed to interact for 18 days and then all animals were returned to the colony. Males' collars were removed immediately and females were placed individually in type IIL mouse cages $(32 \times 20.5 \times 14 \mathrm{~cm})$ to give birth under controlled conditions. Reproductive success (litter size at birth and mean pup body mass at weaning [litter mass at weaning/litter size at weaning]) was measured, and genetic paternity analyses were conducted.

\section{Scent mark analysis}

Photographs of tiles were recorded in a black box $(60 \times 60 \times 80 \mathrm{~cm})$ under UV light, emitted by two $18 \mathrm{~W}$ strip lights $(90 \mathrm{~cm}$, OMNILUX) fixed on the ceiling of the box. The 18 tiles within each territory were photographed in two sets of nine tiles each. Tiles were placed centrally on the bottom of the box in the same order and the same position. Digital photographs were recorded with a camera (Canon EOS 400 D Digital camera, 0.8 in. exposure time and 4.5 aperture value) from a fixed position on top of the box. We recorded the photographs of the first group in trial 1 (see "Experimental design" Section) in JPG format, but we excluded these data from our analyses as the image quality was inadequate and we only analyzed subsequent photographs which were recorded in CR2 format. The box was cleaned with $70 \%$ ethanol after each photo to prevent odor contamination. Photographs were imported into Adobe Photoshop CS5.1 for image analyses and interpolated $(10 \mathrm{~cm} \bumpeq 1,000$ pixel) before a threshold was assigned. To assess the amount of individual male's scent marking, we determined the proportion of freshly marked tile area each day and calculated the sum of the freshly marked area over time starting after female introduction (sum of 5 days). For further analyses, we calculated the difference in the sum of marked tile area within male pairs (hereafter "difference in the two males' scent marking"). In addition, we determined the measurement error in taking three photographs of the same set of tiles and analyzed the photographs with the aforementioned 
method. The marked tile area differed in $<0.05 \%$ between the three photographs.

\section{Genetic paternity analyses}

We conducted paternity analyses to define single- versus multiple-sired litters. DNA was extracted from ear punch samples using a proteinase K/isopropanol protocol (Sambrook et al. 1989). Individuals were genotyped at a minimum of six polymorphic microsatellite loci. If paternity could not be assigned by complete exclusion, we genotyped additional loci. A maximum of 16 microsatellite loci was used for paternity analyses (D11Mit150, D9Mit34, D9Mit135, D17Saha, D17Mit28, D10Mit20, D2Mit252, D6Mit138, D15Mit16, D5Mit25, D19Mit39, D7Mit227, D1Mit456, D2Mit380, D17Mit21, D1Mit404, see Mouse Microsatellite Data Base of Japan) using a Multiplex PCR MasterMix (Qiagen Multiplex PCR kit). Amplification mixes were subjected to a denaturation step at $94{ }^{\circ} \mathrm{C}$ for $15 \mathrm{~min}$ followed by 30 cycles at $94^{\circ} \mathrm{C}$ for $30 \mathrm{~s}, 55^{\circ} \mathrm{C}$ for $90 \mathrm{~s}$, and $72{ }^{\circ} \mathrm{C}$ for $60 \mathrm{~s}$, followed by an elongation step at $72{ }^{\circ} \mathrm{C}$ for $10 \mathrm{~min}$. Amplification products were analyzed using an automated sequencer (Beckman Coulter CEQ 800). Allele scoring was performed using Beckman Coulter CEQ 8000 System software, and allele sizes were determined with SLS+ 400 as size standard. Paternity assignment was assessed using complete exclusion. In addition, paternity results were confirmed with a 95 to $99 \%$ trio confidence (dam-sire-offspring relationship) using the program CERVUS 3.0.3 (Kalinowski et al. 2007).

\section{Statistical analyses}

To test the effect of intrusion treatment and male scent marking on the rate of multiple-sired litters, we ran a generalized linear mixed effects model (GLMM) with a binomial error distribution and a logit link function. We entered paternity (single or multiple) as the dependent variable, trial and treatment as fixed effects, and female body mass, the body mass difference between males and females, and the difference in the two males' scent marking as covariates. As females were repeatedly tested, we included female ID as a random factor to control for nonindependence. Fitness effects of multiple mating were analyzed using a general linear mixed effects model (LMM) with either litter size or mean pup body mass as dependent variables, trial, treatment, and paternity as fixed effects, and female body mass as a covariate. Female ID was again included as a random factor. To test for the relationship between mean pup body mass and litter size under intrusion, we ran a linear model (LM) with mean pup body mass as the dependent variable and litter size as a covariate. Female ID was not included as a random factor as each female was tested only once under intrusion. We tested whether model assumptions (i.e., normally distributed residuals and homogeneity of variances) were fulfilled and transformed
Fig. 2 Frequency of single- and multiple-sired litters in the first (white bars) and second (black bars) trial of the experiment under (a) intrusion treatment and (b) control conditions

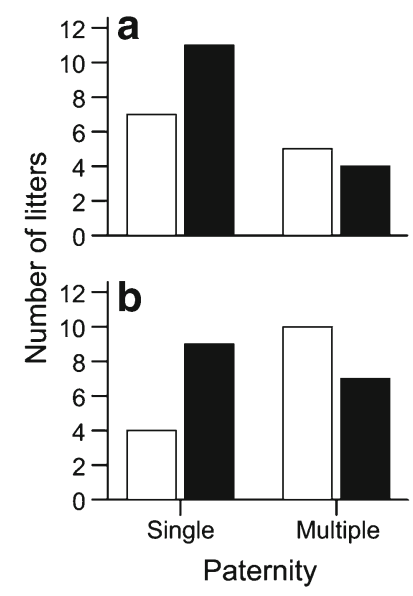

data if necessary. We only included biologically meaningful two-way interactions into all initial models and applied a backward stepwise removal procedure (Grafen and Hails 2002) to avoid problems due to inclusion of nonsignificant terms (Engqvist 2005). Removed variables were reentered one by one to the final model to obtain relevant statistics. Statistical analyses were performed using "R" (version 2.14.1). We implemented linear mixed effects models using the "Ime" function of the "nlme" package, and generalized mixed effects models using the "Imer" function in the "Ime4" package (R Development Core Team 2011).

\section{Results}

We found that 26 of the 57 litters (46\%) had multiple sires; however, the intrusion treatment did not significantly affect multiple paternity (GLMM, $z=-0.283, N=44, P=0.777$, Fig. 2). Yet, the rate of multiple paternity was significantly greater in the first trial when the males were all virgins $(15 / 26$ or $58 \%$ of litters) compared to the second trial ( $11 / 31$ or $35 \%$ of litters) (GLMM, $z=-2.306, N=44, P=0.021$, Fig. 2). Also, paternity was significantly predicted by the difference in the two males' scent marking: we found that multiple paternity was higher when males showed smaller differences in their marking whereas single paternity was higher when the differences in males marking increased (GLMM, $z=-2.472$, $\beta=-0.373, S E=0.151, N=44, P=0.013$, Fig. 3). We found no evidence that female body mass (GLMM, $z=0.911, N=44$, $P=0.362$ ) or the differences in body mass between females and males (GLMM, $z=-0.198, N=44, P=0.843$ ) affected multiple paternity.

We found no overall effect of multiple paternity on litter size (LMM, $F_{1,20}=2.861, N=57, P=0.106$ ), but we found a significant interaction such that the effect of paternity on females' litter size was dependent on the experimental treatment (LMM, $F_{1,20}=4.671, N=57, P=0.043$, Fig. 4). We therefore examined the effect of paternity independent for 


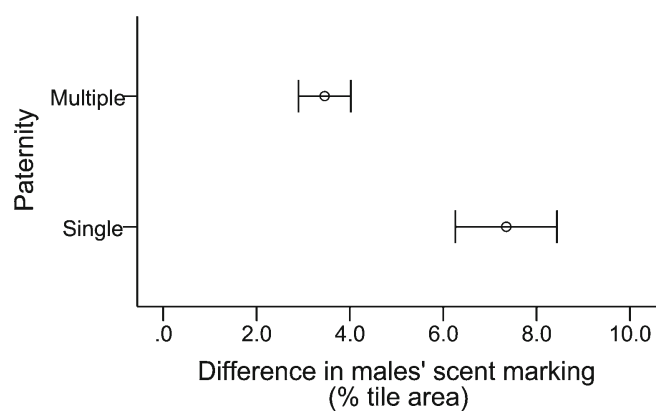

Fig. 3 Difference in the two males' scent marking in single- and multiple-sired litters. Means \pm SE are indicated

the intrusion treatment and the controls. In the intrusion treatment, litter size was significantly larger in multiple than single-sired litters ( $T$ test, $t=-2.267, N=27, P=0.034$ ) whereas paternity had no significant effect on litter size under control conditions ( $T$ test, $t=1.677, N=30$, $P=0.106)$. There was no change in litter size over trials $($ mean \pm SD, $7.26 \pm 1.60)\left(\mathrm{LMM}, F_{1,19}=0.537, N=57\right.$, $P=0.473$ ), but heavier females had larger litters (LMM, $\left.F_{1,20}=6.925, \beta=0.258, S E=0.098, N=57, P=0.016\right)$. Female body mass did not predict mean pup body mass (LMM, $F_{1,18}=0.822, N=56, P=0.376$ ), though mean pup body mass significantly increased from the first to the second trial (from $8.57 \mathrm{~g}$ to $9.32 \mathrm{~g}$ ) (LMM, $F_{1,19}=12.686, N=56$, $P=0.002)$. The interaction between treatment and paternity also had a significant effect on mean pup body mass (LMM, $\left.F_{1,19}=7.739, N=56, P=0.012\right)$. We therefore, again, examined the effect of paternity independent for the intrusion treatment and the controls. In the intrusion treatment, mean pup body mass was significantly smaller in multiplesired litters ( $T$ test, $t=3.391, N=27, P=0.002$ ) whereas in the control treatment we did not find an effect of paternity on mean pup body mass ( $T$ test, $t=-0.529, N=29, P=0.601$ ). Thus, under intrusion, litter size increased whereas mean pup body mass

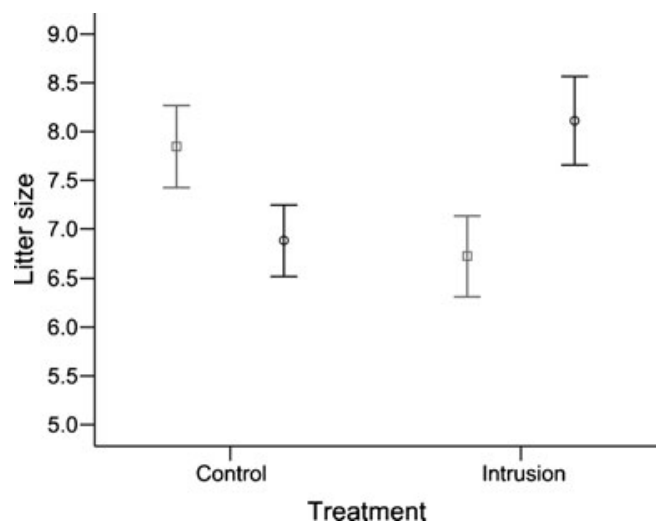

Fig. 4 Litter size of single- (gray, square) and multiple-(black, circle) sired litters under intrusion treatment (single paternity, $6.72 \pm 0.4, N=18$; multiple paternity, $8.11 \pm 0.5, N=9$ ) and control conditions (single paternity, $7.85 \pm 0.4$, $N=13$; multiple paternity, $6.94 \pm 0.4, N=17$ ). Means \pm SE are indicated decreased with multiple paternity. This result could be explained by the marginally nonsignificant negative relationship of litter size and mean pup body mass (LM, $F_{1,25}=3.634$, $\beta=-0.264, S E=0.131, N=27, P=0.068)$.

\section{Discussion}

In total, $46 \%$ ( 26 out of 57 ) of the litters were multiply sired, which is in the high end of the range of multiple paternity found in wild populations of house mice (Dean et al. 2006; Firman and Simmons 2008a). Thus, our findings show that females actively mate multiply when they have the opportunity to freely choose their mates and that they even increase MMM when they are unconstrained by males or other factors in the wild. A previous study on house mice (using offspring from crosses of female laboratory mice (ICR) with wild male mice (Mus musculus domesticus)) observed that $95 \%$ of females actively mated multiply when they could choose to mate with a dominant versus a subordinate male (Rolland et al. 2003). Taken together, these findings support the hypothesis that MMM is due to female choice in house mice, whereas they are inconsistent with the hypothesis that females are forced to mate multiply (sexual coercion) (Wolff 1985; Smuts and Smuts 1993; Clutton-Brock and Parker 1995). We did not explicitly test consistency in MMM (for review, see Nakagawa and Schielzeth 2010) but since multiple paternity was inconsistent across trials, our findings do not provide evidence for consistent individual variation (personality trait or true alternative mating strategy) in multiple paternity. Although multiple paternity was not consistent between treatment versus controls, we found no evidence that multiple paternity was increased in the intrusion treatment, as predicted by the infanticide avoidance hypothesis. Females may have failed to detect any differences between intrusion versus control conditions, though this seems unlikely as the males scent marked significantly more under intrusion compared to control conditions (Thonhauser et al. submitted). Alternatively, females may not assess males' competitive ability based on the frequency of intruders' scent marks, as previously suggested (Rich and Hurst 1998), or males' competitive ability is unrelated to the risk of infanticide, contrary to the "pup defense" hypothesis (Ebensperger 1998). Thus, we cannot exclude the idea that multiple paternity depends on the risk of infanticide or males' perceived quality, especially since we found evidence for both hypotheses, as we explain below.

We found that the rate of multiple paternity was significantly higher in the first compared to the second trial, and females likely faced a higher risk of infanticide during this time. In the first trial, the available males were all still virgins - which are highly infanticidal (Labov 1980; Huck et al. 1982; vom Saal and Howard 1982; Elwood and 
Ostermeyer 1984; Elwood 1985). After copulation and cohabitation with a female, males reduce infanticidal behavior towards their mates' offspring and even other females' pups (Soroker and Terkel 1988). Thus, our finding suggests that female mice mate with multiple males when they encounter virgin males, as predicted by the infanticide avoidance hypothesis. It is not known whether female mice can recognize virgin or other infanticidal males, but females might discriminate differences in their scent, ultrasonic vocalizations, aggression, or other behaviors. Alternatively, the reduction in multiple paternity we observed may be due to other changes in males' behavior over time, unrelated to infanticidal behavior, or changes in females' behavior (despite that experimental females were nonvirgins in both trials). Experience might allow females to avoid male harassment and coercion, though this explanation seems unlikely, as females had a refuge and the differences in body mass between females and males had no influence on the multiple paternity rates. Alternatively, experience may allow females to more effectively defend their offspring against infanticidal males.

We measured males' scent marking since this behavior is expected to influence females' mating preferences, and indeed we found that the difference in the two males' scent marking explained the variation in single versus multiple paternity: in single-sired litters, the males displayed significantly larger differences in their scent marking compared to multiple-sired litters. Males' scent marking is a quality indicator display, and female mice can assess several aspects of quality on the basis of males' scent marking, including social status (Drickamer 1992), competitive ability (Rich and Hurst 1998; Rich and Hurst 1999), and health (Zala et al. 2004). Therefore, this finding suggests that females mate singly when they can detect differences in the males' quality and otherwise they mate multiply. There are several (nonexclusive) hypotheses to explain why females might use such a strategy. First, when females cannot detect differences in males' quality, they may mate multiply to incite sperm competition to increase the genetic quality of their offspring. This idea assumes that males' sperm competitiveness and offspring fitness are genetically correlated and males of high genetic quality sire more viable offspring (intrinsic male quality hypothesis) (Yasui 1997; García-González and Simmons 2005). Second, if male sperm competitiveness is heritable, multiply mated females would have a selective advantage over single mated females as the former are fertilized by the most competitive sperm and will have sons which have superior sperm competitive abilities. A study on house mice showed that polyandrous females can gain fitness benefits by producing sons that achieve high reproductive success in a competitive environment (Firman 2011). Third, if females cannot detect differences in males' quality, MMM could provide females with good genes as females avoid sampling errors caused by inadequate mate discrimination (bet- hedging) (Yasui 1998). Fourth, this result may not be due to female choice, but rather to male sperm competitiveness and male-male interactions. Females may have generally mated multiply, but males' scent marking might have honestly reflected male sperm competitiveness and males that marked at similar rates were equally good in sperm competition, or alternatively, higher marking males could have been better in intimidating rivals, which then in turn transferred less sperm. Future studies are needed that include direct observations of female and male behavior to determine whether our results can be explained by female choice, male-male competition, or an interaction of both.

Finally, we aimed to determine whether multiple paternity enhanced females' reproductive success (litter size) when they are able to select their mates. We found no overall effect of multiple paternity on litter size, but we found an unexpected interaction that masked the effect of paternity on litter size: multiple paternity increased litter size in the intrusion treatment, whereas there was no significant effect in the controls. Thus, although intrusion treatment had no effect on multiple paternity, the effects of multiple paternity on offspring number crucially depended on intrusion where male-male interactions were intensified (and the withinsubject design controls for other potential confounds). This finding suggests that multiple paternity provided reproductive (fitness) benefits for females (e.g., as predicted by fertility assurance, the genetic compatibility, and intrinsic male quality hypotheses), but why did this effect only occur under intrusion treatment? One possible explanation is that males perceived higher competition with intrusion and they increased the number of sperm transferred during mating when they perceive a high risk of sperm competition (Parker 1990, 1998; Wedell et al. 2002). One study on house mice supports this hypothesis (Ramm and Stockley 2009a), but a second study found no support (Ramm and Stockley 2009b) and a third study found that males reduced the number of sperm transferred when mating in the presence of a rival male (Ramm and Stockley 2007). Therefore, it is unclear whether males transfer more sperm when they perceive an increased risk of sperm competition. Moreover, it is unlikely that the females were sperm limited under intrusion but not under control conditions. Interpreting the positive correlation is not straightforward because increasing offspring number does not necessarily enhance females' fitness, contrary to what is often assumed, as there are sexual conflicts over the optimal number of offspring (Penn and Smith 2007), as well as over parental investment. If females engage in multiple mating to reduce the costs from sexual harassment or to reduce infanticide, then increases in litter size from MMM may be costly rather than beneficial for females' fitness. The situation becomes even more complicated when we consider that multiple paternity exacerbates sibling rivalry, as well as sex conflicts, and offspring can potentially influence maternal 
investment and litter size (Royle et al. 2004; Drake et al. 2008). Males and their offspring may influence the number of eggs that females produce or the number of embryos reabsorbed (Hager and Johnstone 2003). An increasing number of studies find that male-male competition influences female mate choice (Wong and Candolin 2005), but this is the first study to our knowledge that shows that the effects of multiple paternity on offspring number depend on females' exposure to male-male interactions. Thus, future studies are needed to determine why the effects of multiple paternity on offspring number depend on male-male interactions and to disentangle the underlying proximate causes and the evolutionary fitness consequences.

Litter size was also influenced by maternal body mass with heavier females producing larger litters. Given that reproduction incurs fitness costs (Reznick 1985), and especially in mammals (Speakman 2008) where gestation is followed by lactation, females in better condition and larger body mass could probably better afford the costs of producing larger litters. Yet, mean pup body mass did not depend on female body mass. Instead, pup body mass significantly increased over trials, indicating that older or more experienced females invested more resources into their average offspring or that they reduce investment when exposed to infanticidal virgin males. Females were repeatedly tested and could gain experience in mate choice and the raising of pups. Although not all females became pregnant during the first trial, all of the females in our study were sexually experienced and gave birth to one litter before used in this experiment. This way we ensured that any differences in the litter sizes between the trials were not due to comparing virgin and nonvirgin females. Pup body mass at weaning is known to correlate with offspring survival in the wild (Baker and Fowler 1992). Our results thus suggest that offspring number depends on female body mass whereas offspring quality (e.g., mean pup body mass) depends on females' age or experience. We also found a negative relationship between litter size and mean pup body mass under intrusion, indicating a negative trade-off between offspring number and quality (Smith and Fretwell 1974).

In summary, we found high rates of multiple paternity even when females can select their mates, indicating that MMM is due to female choice rather than sexual coercion. We found no evidence that females were more likely to give birth to multiplesired litters when males' territories were intruded by neighboring males, as expected if MMM functions to reduce infanticide. We found that multiple paternity was significantly increased in the first trial when the available males were virgins, which are known to be highly infanticidal. However, experimental tests are needed to determine whether MMM is increased when females are exposed to virgin or otherwise infanticidal males. Also, multiple paternity was influenced by the difference in the two males' scent marking, which is a condition-dependent secondary sexual trait (quality indicator). This finding suggests that females mate singly when they are able to detect significant differences in male quality and otherwise they mate multiply (e.g., bet-hedging hypothesis). Finally, we found that multiplesired litters were larger than single-sired litters under intrusion, though studies are needed to determine why this effect only occurred under intrusion when male-male interactions were intensified. Future studies should be aware that the effects of multiple paternity on female reproduction (offspring number) can be masked and even reversed by male-male interactions.

Acknowledgments We thank S. M. Zala and three anonymous reviewers for their valuable comments on earlier versions of the manuscript. We also want to thank T. Klaus and E. K. Straßer for assistance in data collection. Research was supported by the DARPA program (ARO Contract DAAD19-03-1-0215), the FWF (FV_FP27024711); Attila Hettyey was supported by the "Lendület" program of the Hungarian Academy of Sciences (MTA, LP2012-24/2012; www.mta.hu), and S. Raveh was supported by Swiss National Science Foundation fellowships (PBNEP3132801 and PBNEP3-140190).

Conflict of interest The authors declare that they have no conflict of interest.

Ethical standards This study has been discussed and approved by the institutional ethics committee in accordance with Good Scientific Practice guidelines of the University of Veterinary Medicine, Vienna, Austria and national legislation.

Open Access This article is distributed under the terms of the Creative Commons Attribution License which permits any use, distribution, and reproduction in any medium, provided the original author(s) and the source are credited.

\section{References}

Agrell J, Wolff JO, Ylönen H (1998) Counter-strategies to infanticide in mammals: costs and consequences. Oikos 83:507-517

Anderson PK (1961) Density, social structure, and nonsocial environment in house-mouse populations and the implications for regulation of numbers. Trans NY Acad Sci 23:447-451

Arnqvist G, Nilsson T (2000) The evolution of polyandry: multiple mating and female fitness in insects. Anim Behav 60:145-164

Arnqvist G, Rowe L (2005) Sexual conflict in nature. In: Arnqvist G, Rowe L (eds) Sexual conflict. Princeton University Press, pp 1-14

Baker JD, Fowler CW (1992) Pup weight and survival of northern fur seals Callorhinus ursinus. J Zool 227:231-238

Bateman AJ (1948) Intra-sexual selection in Drosophila. Heredity 2:349-368

Bronson FH (1979) The reproductive ecology of the house mouse. Q Rev Biol 54:265-299

Calhoun JB (1962) Population density and social pathology. Sci Am 206:139-148

Clutton-Brock T, McAuliffe K (2009) Female mate choice in mammals. Q Rev Biol 84:3-27

Clutton-Brock TH, Parker GA (1995) Sexual coercion in animal societies. Anim Behav 49:1345-1365

Daly M (1978) Cost of mating. Am Nat 112:771-774

Dean M, Ardlie G, Nachman M (2006) The frequency of multiple paternity suggests that sperm competition is common in house mice (Mus domesticus). Mol Ecol 15:4141-4151 
Dietrich V, Schmoll T, Winkel W, Epplen JT, Lubjuhn T (2004) Pair identity - an important factor concerning variation in extra-pair paternity in the coal tit (Parus ater). Behaviour 141:817-835

Drake A, Fraser D, Weary D (2008) Parent-offspring resource allocation in domestic pigs. Behav Ecol Sociobiol 62:309-319

Drickamer LC (1992) Oestrous female house mice discriminate dominant from subordinate males and sons of dominant from sons of subordinate males by odour cues. Anim Behav 43:868-870

Drickamer LC, Gowaty PA, Holmes CM (2000) Free female mate choice in house mice affects reproductive success and offspring viability and performance. Anim Behav 59:371-378

Ebensperger LA (1998) Strategies and counterstrategies to infanticide in mammals. Biol Rev 73:321-346

Elwood RW (1985) Inhibition of infanticide and onset of paternal care in male mice (Mus musculus). J Comp Psychol 99:457-468

Elwood RW, Ostermeyer MC (1984) Does copulation inhibit infanticide in male rodents? Anim Behav 32:293-294

Engqvist L (2005) The mistreatment of covariate interaction terms in linear model analyses of behavioural and evolutionary ecology studies. Anim Behav 70:967-971

Firman RC (2011) Polyandrous females benefit by producing sons that achieve high reproductive success in a competitive environment. Proc R Soc Lond B 278:2823-2831

Firman RC, Simmons LW (2008a) The frequency of multiple paternity predicts variation in testes size among island populations of house mice. J Evol Biol 21:1524-1533

Firman RC, Simmons LW (2008b) Polyandry facilitates postcopulatory inbreeding avoidance in house mice. Evolution 62:603-611

Firman RC, Simmons LW (2008c) Polyandry, sperm competition, and reproductive success in mice. Behav Ecol 19:695-702

García-González F, Simmons LW (2005) The evolution of polyandry: intrinsic sire effects contribute to embryo viability. J Evol Biol 18:1097-1103

Gosling LM (1982) A reassessment of the function of scent marking in territories. Z Tierpsychol 60:89-118

Gowaty PA (2012) The evolution of multiple mating costs and benefits of polyandry to females and of polygyny to males. Fly 6:3-11

Grafen A, Hails R (2002) Modern statistics for the life sciences. Oxford University Press, Oxford

Hager R, Johnstone RA (2003) The genetic basis of family conflict resolution in mice. Nature 421:533-535

Hoogland JL (1998) Why do Gunnison's prairie dogs copulate with more than one male? Anim Behav 55:351-359

Hosken DJ, Stockley P (2003) Benefits of polyandry: a life history perspective. Evol Biol 33:173-194

Hrdy SB (1979) Infanticide among animals. Ethol Sociobiol 1:13-40

Huck UW, Soltis RL, Coopersmith CB (1982) Infanticide in male laboratory mice: effects of social status, prior sexual experience, and basis for social discrimination between related and unrelated young. Anim Behav 30:1158-1165

Hurst JL (1990) Urine marking in populations of wild house mice, Mus domesticus Rutty. I. Communication between males. Anim Behav 40:209-222

Ilmonen P, Stundner G, Thoß M, Penn D (2009) Females prefer the scent of outbred males: good-genes-as-heterozygosity? BMC Evol Biol 9:104

Jennions MD, Petrie M (2000) Why do females mate multiply? a review of the genetic benefits. Biol Rev 75:21-64

Kalinowski ST, Taper ML, Marschall TC (2007) Revising how the computer program CERVUS accommodates genotyping error increases success in paternity assignment. Mol Ecol 16:1099-1106

Kempenaers B, Verheyen GR, Van den Broeck M, Burke T, Van Broeckhoven C, Dhondt AA (1992) Extra-pair paternity results from female preference for high-quality males in the blue tit. Nature 357:494-496

Klemme I, Ylönen H (2010) Polyandry enhances offspring survival in an infanticidal species. Biol Lett 6:24-26
Labov JB (1980) Factors influencing infanticidal behavior in wild male house mice (Mus musculus). Behav Ecol Sociobiol 6:297-303

Magnhagen C (1991) Predation risk as a cost of reproduction. Trends Ecol Evol 6:183-186

Manning CJ, Dewsbury DA, Wakeland EK, Potts WK (1995) Communal nesting and communal nursing in house mice, Mus musculus domesticus. Anim Behav 50:741-751

McFarlane SE, Lane JE, Taylor RW, Gorrell JC, Coltman DW, Humphries MM, Boutin S, McAdam AG (2011) The heritability of multiple male mating in a promiscuous mammal. Biol Lett 7:368-371

Montero I, Teschke M, Tautz D (2013) Paternal imprinting of mating preferences between natural populations of house mice (Mus musculus domesticus). Mol Ecol 22:2549-2562

Nakagawa S, Schielzeth H (2010) Repeatability for Gaussian and nonGaussian data: a practical guide for biologists. Biol Rev 85:935-956

Oakeshott JG (1974) Social dominance, aggressiveness and mating success among male house mice (Mus musculus). Oecologia 15:143-158

Parker GA (1990) Sperm competition games: sneaks and extra-pair copulations. Proc R Soc Lond B 242:127-133

Parker GA (1998) Sperm competition and the evolution of ejaculates: towards a theory base. In: Birkhead TR, Møller AP (eds) Sperm competition and sexual selection. Academic, London, United Kingdom, pp 3-54

Penn DJ, Smith KR (2007) Differential fitness costs of reproduction between the sexes. Proc Natl Acad Sci U S A 104:553-558

Potts WK, Manning CJ, Wakeland EK (1991) Mating patterns in seminatural populations of mice influenced by MHC genotype. Nature 352:619-621

R Development Core Team (2011) R: A Language and environment for statistical computing. R Foundation for Statistical Computing, Vienna, Austria http://www.R-project.org

Ramm SA, Stockley P (2007) Ejaculate allocation under varying sperm competition risk in the house mouse, Mus musculus domesticus. Behav Ecol 18:491-495

Ramm SA, Stockley P (2009a) Adaptive plasticity of mammalian sperm production in response to social experience. Proc R Soc Lond B 276:745-751

Ramm SA, Stockley P (2009b) Male house mice do not adjust sperm allocation in response to odours from related or unrelated rivals. Anim Behav 78:685-690

Reznick D (1985) Costs of reproduction: an evaluation of the empirical evidence. Oikos 44:257-267

Rich TJ, Hurst JL (1998) Scent marks as reliable signals of the competitive ability of mates. Anim Behav 56:727-735

Rich TJ, Hurst JL (1999) The competing countermarks hypothesis: reliable assessment of competitive ability by potential mates. Anim Behav 58:1027-1037

Rolland C, MacDonald DW, de Fraipont M, Berdoy M (2003) Free female choice in house mice: Leaving best for last. Behaviour 140:1371-1388

Rowe L (1994) The costs of mating and mate choice in water striders. Anim Behav 48:1049-1056

Royle NJ, Hartley IR, Parker GA (2004) Parental investment and family dynamics: interactions between theory and empirical tests. Popul Ecol 46:231-241

Sambrook J, Fritsch EF, Maniatis T (1989) Molecular cloning. A laboratory manual, vol 1-3, 2nd edn. Cold Spring Harbor Lab, Plainview

Simmons LW (2005) The evolution of polyandry: sperm competition, sperm selection, and offspring viability. Annu Rev Ecol Evol Syst $36: 125-146$

Siva-Jothy MT (2006) Trauma, disease and collateral damage: conflict in cimicids. Philos Trans R 361:269-275

Smith CC, Fretwell SD (1974) The optimal balance between size and number of offspring. Am Nat 108:499-506

Smuts BB, Smuts RW (1993) Male aggression and sexual coercion of females in nonhuman primates and other mammals: evidence and theoretical implications. Adv Stud Behav 22:1-63 
Soroker V, Terkel J (1988) Changes in incidence of infanticidal and parental responses during the reproductive cycle in male and female wild mice Mus musculus. Anim Behav 36:1275-1281

Speakman JR (2008) The physiological costs of reproduction in small mammals. Philos Trans R 363:375-398

Taborsky M, Oliveira RF, Brockmann HJ (2008) The evolution of alternative reproductive tactics: concepts and questions. In: Oliveira RF, Taborsky M, Brockmann HJ (eds) Alternative reproductive tactics. An Integrative Approach. Cambridge University Press, pp 1-21

Thornhill R, Alcock J (1983) The evolution of insect mating systems. Harvard Univ. Press, Cambridge

Tregenza T, Wedell N (2002) Polyandrous females avoid costs of inbreeding. Nature 415:71-73

Trivers R (1972) Parental investment and sexual selection. In: Campbell B (ed) Sexual selection and the descent of man. Aldine, Chicago, pp 136-179

vom Saal FS, Howard LS (1982) The regulation of infanticide and parental behavior: implications for reproductive success in male mice. Science 215:1270-1272

Wedell N, Gage MJG, Parker GA (2002) Sperm competition, male prudence and sperm-limited females. Trends Ecol Evol 17:313-320

Whittingham LA, Dunn PO, Stapleton MK (2006) Repeatability of extra-pair mating in tree swallows. Mol Ecol 15:841-849
Wolff RJ (1985) Mating behaviour and female choice: their relation to social structure in wild caught house mice (Mus musculus) housed in a semi-natural environment. J Zool 207:43-51

Wolff JO, Macdonald DW (2004) Promiscuous females protect their offspring. Trends Ecol Evol 19:127-134

Wong BBM, Candolin U (2005) How is female mate choice affected by male competition? Biol Rev 80:559-571

Yasui Y (1997) A "good-sperm" model can explain the evolution of costly multiple mating by females. Am Nat 149:573-584

Yasui Y (1998) The 'genetic benefits' of female multiple mating reconsidered. Trends Ecol Evol 13:246-250

Yasui Y (2001) Female multiple mating as a genetic bet-hedging strategy when mate choice criteria are unreliable. Ecol Res 16:605-616

Zala SM, Potts WK, Penn DJ (2004) Scent-marking displays provide honest signals of health and infection. Behav Ecol 15:338-344

Zala SM, Chan B, Bilbo SD, Potts WK, Nelson RJ, Penn DJ (2008a) Genetic resistance to infection influences a male's sexual attractiveness and modulation of testosterone. Brain Behav Immun 22:381-387

Zala SM, Potts WK, Penn DJ (2008b) Exposing males to female scent increases the cost of controlling Salmonella infection in wild house mice. Behav Ecol Sociobiol 62:895-900

Zeh JA, Zeh DW (1997) The evolution of polyandry II: post-copulatory defences against genetic incompatibility. Proc R Soc Lond B 264:69-75 